\title{
Mindfulness as practice: A network analysis of FMI data
}

Joseph H. Smith

Heather M. Kempton

Matt N. Williams

Clifford van Ommen

Affiliation for all authors: School of Psychology, Massey University, Auckland.

Correspondence can be addressed to:

Joseph H. Smith, jsmith.massey [at] gmail [dot] com

or

Heather M. Kempton, h.kempton [at] massey [dot] ac [dot] nz

This is the peer reviewed (accepted) version of the following article: Smith, J. H., Kempton, H. M., Williams, M. N., \& van Ommen, C. (2021). Mindfulness as practice: A network analysis of FMI data. Counselling and Psychotherapy Research, 21(4), 899-909, which has been published in final form at https://doi.org/10.1002/capr.12400. This article may be used for non-commercial purposes in accordance with Wiley Terms and Conditions for Use of Self-Archived Versions. This article may not be enhanced, enriched or otherwise transformed into a derivative work, without express permission from Wiley or by statutory rights under applicable legislation. Copyright notices must not be removed, obscured or modified. The article must be linked to Wiley's version of record on Wiley Online Library and any embedding, framing or otherwise making available the article or pages thereof by third parties from platforms, services and websites other than Wiley Online Library must be prohibited.

This manuscript has been slightly reformatted for sharing (e.g., tables and figures have been inserted within the main text, and links to supporting information have been added). 


\begin{abstract}
Mindfulness research implicitly conceives of mindfulness as an identifiable real 'thing' that exists beyond what is directly observed. Recently, a new methodology has been developed which allows mindfulness to be modelled as a complex system or network at the level of self-report. In these models, items become a network's nodes, and the statistical relations between them, edges. Interpreted causally, nodes are thought to increasingly influence each other via their edges, such that they become increasingly correlated. This study hypothesises that at a cross-sectional level, this may result in differences in overall network connectivity (density) between practitioners and nonpractitioners.
\end{abstract}

Mindfulness networks were estimated for practitioners and non-practitioners using the Friedberg Mindfulness Inventory (FMI). A total of 371 regular mindfulness practitioners and 283 non-practitioners (including 59 irregular practitioners) were recruited online from Amazon Mechanical Turk.

Comparisons of practitioners' and non-practitioners' networks indicated that network density did not significantly differ, whereas evidence was found in support of a significant difference in network structure. An exploratory analysis revealed substantive group differences in how items (practices) were connected. In particular, the practice of Acceptance appeared more central to the practitioners' network relative to the nonpractitioners network, indicating Acceptance may be particularly useful for engagement in mindfulness practices.

The study supports investigating mindfulness as a complex network at the level of self-report, with implications for how the development of mindfulness is 
conceptualised. The lack of difference in network density indicates that research is needed to examine network dynamics in the context of regular mindfulness practice.

Keywords: Network Analysis, Psychological Networks, Mindfulness, Latent Variables, Network Comparison Test

\section{Brief Points:}

- Mindfulness can be modelled as emerging from a network of practices.

- Differences in how the practice of Acceptance was connected distinguished the groups.

- Differences in network structure may index differences in item comprehension. 


\subsection{Introduction}

Psychometrics employs statistical models to connect external observable behaviour to statistical terms/constructs with precision. These statistical constructs are often equated with underlying traits which are used to explain behaviour (Borsboom, 2006). The term trait mindfulness is indebted to this approach; a term broadly referring to the stable or regular ability to attend to the present moment with a particular intention, variously described as compassionate, accepting and/or non-judging (Brown et al., 2007). The task of measuring trait mindfulness has necessitated the development of reliable selfreport measures. These measures have sought to determine whether a given practice or mindfulness intervention is actually cultivating mindfulness, as opposed to some other quality. Trait mindfulness measures have been shown to be sensitive to change with mindfulness training (e.g., Khoury et al., 2013; Quaglia et al., 2016), and these changes have been shown to mediate important outcomes (e.g., Bränström et al., 2012).

The development of trait mindfulness measures has typically involved choosing items representing observable behaviour considered relevant to mindfulness. Once a suitable set of items has been developed, the item set (now a measure) has then been applied to a sample population, following which statistical techniques known as principal component analysis (PCA) or factor analysis (FA) are typically performed on the data (e.g., Pelham et al, 2019; Walach et al., 2006). Both these techniques return a parsimonious set of factors or principal components which account for the (covariance) patterns observed in the data. These statistical products are then treated as equivalent 
to the theoretical attribute/s of mindfulness (the retrieval of multiple factors or components will typically be interpreted as facets/sub-components of mindfulness in what becomes a hierarchical model). Those attributes relevant to the statistical construct/s are then generalised to the theoretical attribute/s (mindfulness); hence trait mindfulness and its sub-components comes to be seen as a sum-score or dosedependent type entities, which induces a linear ordering of people into more or less.

\subsection{Factor Analysis and Principal Component Analysis}

Despite FA and PCA often being interpreted interchangeably, the distinction is relevant for the conceptualisation of mindfulness. For the sake of simplicity, only unidimensional models will be described. FA involves fitting a Common Factor Model (CFM) to the data: provided a set of observed variables (i.e., questionnaire items) share some variance, a common factor constituting this shared variance can be obtained (irrespective of its cause, van Bork, 2019). In this model, unique variance such as the marginal associations between items, are assumed conditional on the common factor (also termed a latent variable). Conditioning on this factor should render items independent, an assumption known as local independence. By way of contrast, PCA does not use local independence as a criterion; rather PCA composes a principal component that takes all variance in the observed variables into account, as opposed to just shared variance.

When a researcher wishes to explain rather than describe mindfulness, a casual interpretation is typically made of these models. Mindfulness questionnaires do not involve an arbitrary selection of items, and hence meaningful casual associations are assumed between selected observable items and the retrieved factors or principal 
components. The nature of this association is what distinguishes the two models: In FA, the covariance in responses to items can be assumed an effect of an underlying latent variable (i.e., the retrieved factor; see Figure 1). This is termed a common cause or reflective interpretation (Bollen \& Lennox, 1991). Although the CFM cannot confirm such an interpretation, it does test precisely the kind of constraints it demands. As such, poor model fit, such as by way of violations of local independence, can be adduced as evidence against a common cause hypothesis. Conversely, good fit can be adduced as evidence in support of a common cause hypothesis.
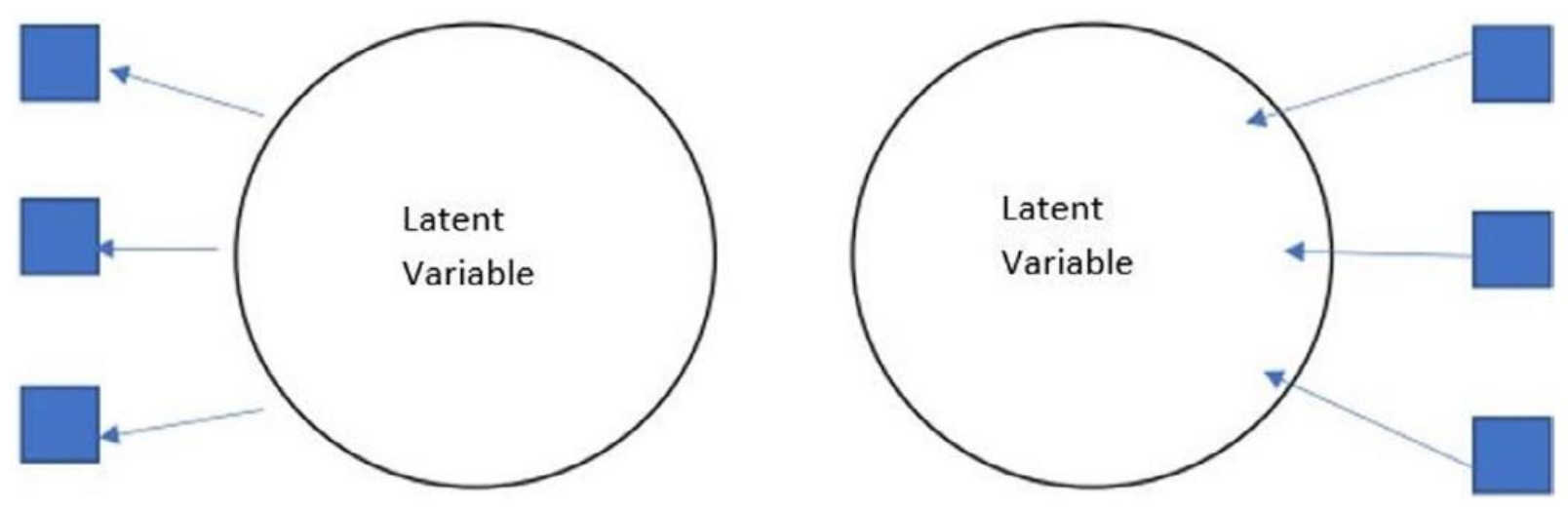

Figure 1. Reflective (left) and formative (right) models relating a construct to indicators (blue). Causality travels from the latent variable to observable items in the reflective model, and from the indicators to the latent variable in the formative model.

In turn, a common cause hypothesis usually entails a commitment to realism, as things must generally be considered to really exist if they are to cause changes in other things (Borsboom et al., 2003; Edwards \& Bagozzi, 2000). A common cause interpretation of trait mindfulness hence involves assumptions that 1) the statistical 
factor/trait construct refers to something really existing outside of the CFM model, and 2) that this real entity is the cause of covariance observed within the items in the model. With respect to mindfulness, these assumptions are crucial, for they justify the use of different mindfulness measures on different datasets to discover (a universal, real and independent) mindfulness. It follows that results can then build on themselves and strengthen theory. Causal euphemisms whereby trait mindfulness fosters, enhances, activates, yields improved, determines and leads to various outcomes also follow from this. Likewise, for biological (e.g., Black \& Slavich, 2016), neurobiological (e.g., Holzel et al., 2011) and genetic investigations (e.g., Waszczuk et al., 2015) into mindfulness. In all cases, a really existing, causal, underlying mindfulness entity is endorsed. This process of making real a statistical term is called reification.

PCA is less suited to the type of realism described as its latent variable/s (principal component/s) are considered common effects of the observable items (see Figure 1). These latent variables are less suited to realist demands, for there very identities change as items are added or omitted (Bollen \& Lennox, 1991). The identity of mindfulness as a formative construct is thus much more fluid: mindfulness is plural and depends on whatever items you happen to measure.

\subsection{Network Models}

Recently, a new psychometric network mode/ has been developed for self-report data (e.g., Borsboom, 2017, Eskamp et al., 2018). In these networks, questionnaire items are represented as nodes, and the statistical associations between them, edges. In a network model, the (covariance) patterns in a dataset are explained not by recourse to latent variable/s functioning as either common causes (i.e., a reflective model) or 
common effects. Rather, in the network model, the covariance in responses to items is explained by recourse to direct causal associations between items (Schmittmann et al., 2013). In this way, the psychological attribute of mindfulness is conceived of as being constituted by a casual network of relevant practices. Note that "practice" is used in this article to refer to individual FMI items, as the underlying questions are formulated in a way that respondents confirm whether they partake in a particular behaviour (i.e. they practice it). To use items from the popular Freidburg Mindfulness Inventory (FMl; Walach et al., 2006) as an example, a network model would assume that a correlation between, say, the practice being "friendly to myself when things go wrong" (FMI, item 9) and being able to "accept unpleasant experiences" (FMI, item 8) is plausibly explained by direct causal effects of practices on one another, rather than a shared effect of a common underlying trait (i.e. self-compassion may directly foster acceptance, or vice versa). With cross-sectional data, associations such as the above are considered potentially casual on the basis that these associations are predictive (direction unspecified; Epskamp et al., 2018). Of course, the casual assumption can be strengthened when temporal data is available, by which the network can be termed dynamic. In endorsing the network approach, it is not asserted that the working mindfulness researcher necessarily endorses the idea that mindfulness exists as a real entity standing beyond observable practice, functioning as either a cause of such practice, or the effect of it. What is highlighted is only that models and language used convey these ideas. In actuality, the issues being discussed are rarely (if ever) made explicit (see also van Dam et al., 2018). 
In support of this contention, many researchers have explicitly called for mindfulness to be considered from a network perspective. Citing concerns with the reification of mindfulness, Garland et al (2015a) proposed that "it may be fruitful, for instance, to consider that there may be no actual entity called 'mindfulness', but rather a network of interacting cognitive and affective processes...that we, for scholarly convenience, label 'mindfulness'” (p. 2). Likewise, van Dam et al (2017) have called for mindfulness research to move from efforts to obtain single unitary measures to datadriven dynamic (i.e. network) approaches. Chiesa (2013) has also critiqued extant measures for failing to adequately capture the synergy and interdependence of practices. Finally, Shankland et al., (2017) have recommended that a "new operational model of mindfulness... be developed and empirically tested while taking into account the components of mindfulness and their interactions" (p. 127). To this end, a number of network models of mindfulness already exist in the literature. Garland and colleagues $(2010,2015 b)$ have proposed increasingly more integrated system theories of mindfulness in which various practices feedback into each other, fostering positive states of mind. A more neurobiological account is also found in Vago and Silbersweig's (2012) influential systems-based model which conceives of mindfulness in part as a multidimensional skill set which, in interaction, reduces self-processing biases and fosters a healthy mind.

By investigating practices qua practices, network models tend to converge on the idea that mindfulness is practice, and not something standing apart from or independent of practice (i.e., as an independent cause or effect). In short, mindfulness is granted no essential independent character: the way to comprehend mindfulness is sought in the 
genesis and flourishing of its observable practices over time. Put differently, the ends of mindfulness are simply its means at a later point in time. This formulation is consonant with typical mindfulness instructions which direct the practitioner solely to the means of any given practice which carries the prefix mindful; for example, one does not focus on the destination in mindful walking, but exclusively the means. Secondly, it is consistent with the observation that the very qualities which arise from mindfulness (e.g. being open to the present, non-judgment, self-compassion etc.), constitute precisely those required to cultivate the practice in the first place. Finally, it is worth noting that it affirms the canonical Buddhist doctrine of impermanence; namely, that all physical and mental events are not metaphysically real.

A principal application of psychological networks has been the identification of important nodes. Important nodes are those in which changes (perhaps by way of local manipulations) may have a proportionally larger influence on the functioning of the network as a whole, relative to the other nodes (although see Bringmann et al., 2019). Hence, "node centrality" (the number of connections to a node and their strength) has often been considered a measure of a nodes importance. So-called global network properties have also been investigated such as overall network density (the sum total strength of all the connections in a network) and network structure. In theory, denser networks may facilitate greater feedback among nodes allowing for stable states to emerge. Some support for this idea has come from the application of network psychometrics to psychopathology. In this literature, several network studies using different types of data have converged on the idea that greater connectivity may be 
associated with greater symptom severity, interpreted as the development of a stable psychopathological disorder (e.g. van Borkulo et al., 2015; Wigman et al., 2013).

A search of popular psychology databases (PSYCINFO, Web of Science, Google Scholar) revealed only one application of "Psychological Networks" and/or "Network Psychometrics" to the field of "Mindfulness". Roca, Diez, Castellanos and Vazquez (2019) used network analysis to explore the effects of a standardized mindfulness intervention (Mindfulness Based Stress Reduction; MBSR) on the network reorganization of relevant psychological nodes (i.e., mindfulness, compassion, psychological well-being, psychological distress and emotional-cognitive control). They reported several topological changes which they attributed to participation in the MBSR programme. Amongst others, self-compassion became more strongly connected after MBSR and, similarly, the interconnections between wellbeing measures increased after MBSR. Finally, a node representing cognitive reappraisal shifted from being connected with more maladaptive processes (e.g. rumination) to mindfulness and wellbeing measures after the MBSR.

Our study assumes that relevant mindfulness practices may develop into a stable capacity state analogous to how psychopathology network studies have conceptualised symptoms developing into a stable disorder state. Specifically, it presupposes that dependencies between practices will strengthen over time in practitioners engaged in regular mindfulness. At the cross-sectional level, this might manifest in increased network density in practitioners relative to that which might be observed in nonpractitioners. The current study thus proposed to investigate the hypothesis that the networks of regular practitioners will be characterised by greater overall connectivity 
(density) than the networks of non-practicing individuals. An exploratory analysis of network structure was also conducted (i.e., investigating which connections between nodes are present, and how strong those connections are). In short, the study attempts to comprehend mindfulness in the genesis (i.e. an exploratory analysis to reveal potential causal sequences) and flourishing (i.e. testing for a significant difference in density) of its practices within the constraints of a cross-sectional research design.

\subsection{Method}

\subsection{Participants}

After removing missing data (see Procedures section), participants consisted of 654 registered users (368 practitioners, 224 non-practitioners and 59 irregular practitioners) of an online subject pool known as Amazon Mechanical Turk (MTurk). The study restricted respondents to US workers over the age of 18 whom had a MTurk study approval rate of greater than $95 \%$. All participants were compensated US $\$ 0.80$ after completing a single online survey session. This study was part of a larger study which involved collecting data using two mindfulness measures. The current study involves the analysis of one of these measures.

Based on recommendations in the literature, recruitment aimed for three persons per parameter (Epskamp et al, 2018). For a 14-node network there are 105 possible parameters to estimate ( 14 threshold parameters and $14 \times 13 / 2=91$ pairwise association parameters), and hence selection aimed to recruit 315 participants per group. Due to these statistical requirements the irregular practitioners were combined with the non-practitioners during data analysis after determining no significant differences between these two groups in FMI scores. Formal considerations of power 
analysis in the network context are still being developed in the literature, and the reader is directed to Epskamp et al (2018).

The socio-demographic information for all groups is provided in Table 1. Overall, the sample was primarily Caucasian, (76\%), aged 63 between $25-35$ years $(49 \%)$, with either a four-year college degree (35\%) or some college education (28\%). Respondents most frequently reported having no religious affiliation (52\%), with the second largest group being protestant Christian (24\%). There were slightly more males (54\%) than females $(46 \%)$ in the total sample. These differences generally characterised all three groups.

Table 1

Demographics and Characteristics

\begin{tabular}{|l|l|l|l|l|}
\hline & $\begin{array}{l}\text { Practice } \\
(\mathrm{n}=364)\end{array}$ & $\begin{array}{l}\text { Controls } \\
(\mathrm{n}=224)\end{array}$ & $\begin{array}{l}\text { Irregular } \\
(\mathrm{n}=59)\end{array}$ & $\begin{array}{l}\text { Total } \\
(\mathrm{n}=654)\end{array}$ \\
\hline $\begin{array}{l}\text { Age, } n(\%) \\
15-24\end{array}$ & $66(18)$ & $27(12)$ & $10(17)$ & $103(16)$ \\
\hline $25-34$ & $188(52)$ & $95(43)$ & $29(50)$ & $312(48)$ \\
\hline $35-44$ & $62(17)$ & $66(30)$ & $11(19)$ & $139(22)$ \\
\hline $45-54$ & $29(8)$ & $21(10)$ & $4(7)$ & $54(8)$ \\
\hline $55-64$ & $17(4)$ & $11(5)$ & $3(5)$ & $30(5)$ \\
\hline 65 plus & $3(1)$ & $2(1)$ & $2(3)$ & $7(1)$ \\
\hline $\begin{array}{l}\text { Education, } n(\%) \\
\text { Less than high }\end{array}$ & $1(0)$ & $0(0)$ & $0(0)$ & $1(0)$ \\
\hline $\begin{array}{l}\text { school } \\
\text { High School }\end{array}$ & $37(10)$ & $35(16)$ & $5(9)$ & $77(12)$ \\
\hline $\begin{array}{l}\text { Some College } \\
2 \text {-year College }\end{array}$ & $102(28)$ & $62(28)$ & $19(32)$ & $183(28)$ \\
\hline $\begin{array}{l}\text { Degree } \\
\text { 4-year College }\end{array}$ & $130(36)$ & $23(10)$ & $5(9)$ & $86(13)$ \\
Degree & $74(33)$ & $19(32)$ & $223(35)$ \\
\hline Master's Degree & $31(9)$ & $21(10)$ & $8(14)$ & $60(9)$ \\
\hline Doctoral Degree & $2(1)$ & $4(2)$ & $2(3)$ & $8(1)$ \\
\hline $\begin{array}{l}\text { Professional } \\
\text { Degree }\end{array}$ & $3(1)$ & $3(1)$ & $1(2)$ & $7(1)$ \\
\hline Gender, $\mathrm{n}(\%)$ & & & & \\
\hline
\end{tabular}




\begin{tabular}{|l|l|l|l|l|}
\hline Male & $201(54)$ & $119(54)$ & $30(51)$ & $350(54$ \\
\hline Female & $163(45)$ & $103(46)$ & $29(49)$ & $295(46)$ \\
\hline \begin{tabular}{l} 
Race, $n(\%)$ \\
\hline White/Caucasian
\end{tabular} & $265(73)$ & $174(79)$ & $49(83)$ & $488(76)$ \\
\hline $\begin{array}{l}\text { African } \\
\text { American }\end{array}$ & $32(9)$ & $20(9)$ & $2(3)$ & $54(8)$ \\
\hline Hispanic & $2(6)$ & $9(4)$ & $1(2)$ & $30(5)$ \\
\hline Asian & $39(11)$ & $16(7)$ & $7(12)$ & $62(10)$ \\
\hline Native American & $3(1)$ & 0 & 0 & $3(1)$ \\
\hline $\begin{array}{l}\text { Other } \\
\text { Religious }\end{array}$ & $5(1)$ & $3(1)$ & 0 & $8(1)$ \\
\hline $\begin{array}{l}\text { Affiliation, } n(\%) \\
\text { None }\end{array}$ & $182(50)$ & $129(58)$ & $30(51)$ & $341(53)$ \\
\hline $\begin{array}{l}\text { Protestant } \\
\text { Christian }\end{array}$ & $88(24)$ & $57(26)$ & $14(24)$ & $156(24)$ \\
\hline $\begin{array}{l}\text { Roman Catholic } \\
\text { Buddhist }\end{array}$ & $33(9)$ & $22(10)$ & $10(17)$ & $65(10)$ \\
\hline Other & $20(6)$ & $0(0)$ & $2(3)$ & $22(3)$ \\
\hline
\end{tabular}

\section{Procedure.}

The study was listed twice on MTurk with descriptions tailored to maximise recruitment of either practitioners or non-practitioners. (See Table S1 in the Supporting Information). Participants could complete either listing, but not both. On selecting a listing, participants were requested to identify whether they were regular, irregular or non-practitioners via a drop down menu. In 23 cases, participants did not answer any of the survey questions and were excluded from analysis. In four cases, participants completed a survey twice (once incomplete and once complete.) Only the completed entries were used in analysis.

\section{Measures.}

The Freidburg Mindfulness Inventory (FMl; Walach et al., 2006), in its short form, is a 14-item scale designed to measure mindfulness as a stable trait. The FMI-14 has 
been shown to be useful in distinguishing between participants with and without meditation experience (Sauer et al., 2011; Sauer et al., 2015; Walach et al., 2006). The scale was initially developed as a unidimensional scale; however, research also supports a two-factor solution of Presence and Acceptance (e.g. Kohls et al., 2009; Presence FMI items 1, 2, 3, 5, 7, 10; Acceptance FMI items 4, 6, 8, 9, 11, 12, 14). Presence is generally thought to reflect the awareness of stimuli in the subjective now, and Acceptance, a non-judgmental stance toward all kinds of experience. The FMI utilises 4-point rating scale ("rarely", "occasionally", "fairly often" and "almost always"). The FMI has been validated not only with classical psychometric analyses such as exploratory and confirmatory factor analyses (Kohls et al., 2009) but also with item response theory (Sauer et al., 2011) and machine learning algorithms (Sauer et al., 2015). The latter method involved using predictive algorithms to scrutinize the degree to which FMI items were able to predict whether the participants were practicing mindfulness on a regular basis or not. The FMI was considered appropriate for the current study given that it was designed to be acceptable to both practitioners and non-practitioners, whilst being relatively brief which was required for adequate power in the study.

\section{Data Analysis.}

All analyses were conducted using the $R$ statistical software, version 3.5.3 ( $R$ Core Team, 2019). Networks were estimated and visualised using the $R$ package qgraph, version 1.5 (Epskamp et al., 2012). All R code and the dataset are available on the Open Science Framework for reproduction and 
replication purposes (https://osf.io/vr3ai/). Information which may identify the participants was removed.

The basic procedure for estimating and visualising the practitioner and nonpractitioner (irregular practitioners included in latter) mindfulness networks involved estimating Gaussian Graphical Models (GGM) using the estimated correlation matrix of the FMI data as input. The GGM forms an undirected network model in which edges represent partial correlations. The networks were regularised using the glasso algorithm (Friedman et al., 2014) which functions to remove arbitrarily small correlations. This allows only a relatively small number of edges to explain the covariation structure of the data. Regularisation of networks is controlled with a gamma tuning parameter ( $\mathrm{v}$ ), typically set between 0 and 0.5 . Higher values select sparser models, but at the risk of missing some true edges. Lower values maximise sensitivity and are better suited to discovery questions. For more information on the estimation and visualization of GGMs, the reader is directed to the tutorial in Jones et al. (2018).

Differences in network connectivity (density) and structure were calculated using the package Network Comparison Test (NCT; von Borkulo et al., 2022). The NCT estimates networks with Pearson's correlations and requires equal sample sizes, which were not obtained in this study. Rather than dropping participants from one group, a two-step procedure was used which maximised power. Firstly, the irregular and non-practitioner samples were combined to increase the sample size of the nonpracticing group. Visual inspection and an analysis of path weights revealed this to be a viable strategy (Figure S1). The second step used a bootstrap procedure to create equal groups in a procedure similar to that used by Rhemtulla et al., (2016). This 
involved drawing 500 resamples of $n=325$ (with replacement) from each group (the sample size of 325 was chosen because it was the average of the two samples combined). NCTs were then performed on each resample, such that a range of 500 results were generated, and the median value reported. The y parameter was set to 0 to maximise the chances of detecting differences.

The exploratory analysis made use of the R package Exploratory Graphical Analysis (EGA version 0.2; Golino \& Epskamp, 2017) to investigate community structures of each groups' network-i.e., how nodes connected to one another, and whether any subsets of nodes clustered into densely connected communities. Strength centrality was calculated using the centrality Plot function, implemented in qgraph (Epskamp et al., 2012) and z-scores were used to aid comparison. Briefly, strength centrality provides a measure of the likelihood that activation of a given node will be followed by activation of other nodes. Highly central nodes are often considered important targets for any proposed network interventions.

Networks used in the exploratory analysis were estimated with polychoric correlations using a tuning parameter of .5 , as recommended by Epskamp et al., 2018. The edge lists of groups network were correlated to provide another difference measure known as the coefficint of similarity (Rhemtulla et al., 2016; a correlation of 1 implies that the networks are perfectly linearly related). A number of procedures were used to determine the stability of the networks. Edge weight stability and the accuracy of the order of centrality were explored using procedures recommended by Epskamp et al (2018; Figures S2 \& S3). Networks were estimated with Spearman's correlations to determine the stability of polychoric correlations where 
sampling may have been reduced (i.e., pairwise cross-tabulations of items contain less than 10 cases; Epskamp et al., 2018; Figure S4). Finally, range restriction was investigated by correlating centrality and standard deviation and inspecting plots for floor and ceiling effects (Figure S5; see Terluin, de Boer and de Vet., 2016).

\section{Results}

\section{General Characteristic}

A one-way ANOVA was conducted to compare the self-attributed total FMI Mindfulness scores across the three groups. There was a significant difference in total mindfulness levels across the groups $(F(2,648)=57.24, p<.001)$. Post hoc comparisons using the Tukey HSD test indicated that the mean score for practitioners $(M=40.35, S D=7.10)$ was significantly different to the mean score of non-practitioners $(M=34.19, S D=7.68)$, $t=6.16, p<.05$, and irregular practitioners $(M=37.64, S D=7.98), t=6.5, p<.05$. No significant differences were observed between irregular practitioners and nonpractitioners $(\mathrm{t}=.34, \mathrm{p}<.95)$.

\section{Do the Networks Differ in Density and Structure?}

To determine whether the group's networks significantly differed in density (the sum total of connections and their strength in a network) and structure (the topographical configuration), the median effect size and $p$ value of 500 NCT tests of density difference was ascertained. The (gamma) tuning parameter was set to 0 to maximise the sensitivity of the NCT to detect differences. Only $15 \%$ of these NCTs found significant $(p<.05)$ group differences in network density 
(median $S /$ span $>=.76$, median $p=.33$ ). This means that there was no evidence of a difference in network density across the practitioner and non-practitioner groups.

Evidence did exist to support a difference in the group's network structures however. Sixty two \% of the 500 resampled NCTs found significant differences $(p<.05)$ in network structures (median $L=.24$, median $p=.03$ ). This procedure was repeated when the (gamma) tuning parameter was set to higher levels (i.e., selecting a preference for sparser networks) to check for the robustness. Only $58 \%$ (290 out of 500 networks) of the resampled networks were found to significantly differ at the gamma level of .25 (median $L=.23$, median $p=$ .04 ) and $54 \%$ differed at the gamma level of.5 (median $L=.23$, median $p=.04$ ).

\section{An exploratory Analysis of Network Structure}

Figure 2 shows practitioner and non-practitioner FMI regularized (glasso) networks. The corresponding items, descriptions, abbreviations, sample means, and standard deviations for each network are presented in Table 2. The results of the centrality analysis are shown in Figure 3. The networks were considered moderately accurately estimated, such that only the strongest paths differed from the weakest (Figure S2). Analysis of centrality suggested that only practice strength could be interpreted and compared with some confidence (igure S3).

\section{Table 2}

FMI items, content, abbreviations, means, and standard deviations.

\begin{tabular}{|c|c|c|c|c|}
\hline Item & Item content & Abbreviations & $\begin{array}{l}\text { Practitioners } \\
\qquad \begin{array}{r}(n=368) \\
M(S D)\end{array}\end{array}$ & $\begin{array}{r}\text { Non } \\
\text { practitioners } \\
(n=224) \\
M(S D)\end{array}$ \\
\hline
\end{tabular}




\begin{tabular}{|c|c|c|c|c|}
\hline FMI1 & $\begin{array}{l}\text { I am open to the } \\
\text { experience of the } \\
\text { present } \\
\text { moment }\end{array}$ & $\begin{array}{l}\text { Openness to } \\
\text { Present (OpP) }\end{array}$ & $3.11(0.68)$ & $2.80(0.77)$ \\
\hline FMI2 & $\begin{array}{l}\text { I sense my body, } \\
\text { whether } \\
\text { eating, cooking, } \\
\text { cleaning } \\
\text { or talking }\end{array}$ & $\begin{array}{l}\text { Sensing the Body } \\
\text { (Sen) }\end{array}$ & $2.86(0.81)$ & $2 . .29(0.96)$ \\
\hline FMI3 & $\begin{array}{l}\text { When I notice an } \\
\text { absence } \\
\text { of mind, I gently } \\
\text { return to } \\
\text { the experience of } \\
\text { the here } \\
\text { and now }\end{array}$ & $\begin{array}{l}\text { Returning to the } \\
\text { Present (RtP) }\end{array}$ & $2.80(0.77)$ & $2.20(0.95)$ \\
\hline FMI4 & $\begin{array}{l}\text { I am able to } \\
\text { appreciate } \\
\text { myself }\end{array}$ & $\begin{array}{l}\text { Self-Appreciation } \\
\text { (SAp) }\end{array}$ & $3.05(0.81)$ & $2.64(0.93)$ \\
\hline FMI5 & $\begin{array}{l}\text { I pay attention to } \\
\text { what's } \\
\text { behind my actions }\end{array}$ & $\begin{array}{l}\text { Attending to } \\
\text { actions (AtA) }\end{array}$ & $3.10(0.75)$ & $2.67(0.87)$ \\
\hline FMI6 & $\begin{array}{l}\text { I see my mistakes } \\
\text { and } \\
\text { difficulties without } \\
\text { judging them }\end{array}$ & $\begin{array}{l}\text { Being Non } \\
\text { Judgemental (NJ) }\end{array}$ & $2.67(0.81)$ & $2.15(0.92)$ \\
\hline FMI7 & $\begin{array}{l}\text { I feel connected to } \\
\text { my } \\
\text { experience in the } \\
\text { here } \\
\text { and-now }\end{array}$ & $\begin{array}{l}\text { Connected to the } \\
\text { Present (CnP) }\end{array}$ & $3.00(0.73)$ & $2.54(0.82)$ \\
\hline FMI8 & $\begin{array}{l}\text { I accept unpleasant } \\
\text { experiences }\end{array}$ & Acceptance (Acc) & $2.80(0.83)$ & $2.48(0.87)$ \\
\hline FMI9 & $\begin{array}{l}\text { I am friendly to } \\
\text { myself } \\
\text { when things go } \\
\text { wrong }\end{array}$ & $\begin{array}{l}\text { Self-Kindness } \\
\text { (SfK) }\end{array}$ & $2.67(.90)$ & $2.36(0.95)$ \\
\hline FMl10 & $\begin{array}{l}\text { I watch my feelings } \\
\text { without getting lost } \\
\text { in } \\
\text { them }\end{array}$ & $\begin{array}{l}\text { De-centered } \\
\text { Observation (Obs) }\end{array}$ & $2.84(0.80)$ & $2.39(0.96)$ \\
\hline FMl11 & $\begin{array}{l}\text { In difficult situations, } \\
\text { I } \\
\text { can pause without } \\
\text { immediately } \\
\text { Reacting }\end{array}$ & $\begin{array}{l}\text { Non-Reactivity } \\
(N R)\end{array}$ & $2.86(0.80)$ & $2.51(0.88)$ \\
\hline
\end{tabular}




\begin{tabular}{|c|c|c|c|c|}
\hline FMI12 & $\begin{array}{l}\text { I experience } \\
\text { moments of } \\
\text { inner peace and } \\
\text { ease, } \\
\text { even when things } \\
\text { get } \\
\text { hectic and stressful }\end{array}$ & $\begin{array}{l}\text { Experiencing } \\
\text { Inner Peace (IP) }\end{array}$ & $2.76(0.84)$ & $2.09(0.87)$ \\
\hline${ }^{*} \mathrm{FMl13}$ & $\begin{array}{l}\text { I am impatient with } \\
\text { myself and with } \\
\text { others }\end{array}$ & Patience (Pat) & $3.03(0.88)$ & $2.95(0.90)$ \\
\hline FMl14 & $\begin{array}{l}\text { I am able to smile } \\
\text { when } \\
\text { I notice how I } \\
\text { sometimes } \\
\text { make life difficult }\end{array}$ & $\begin{array}{l}\text { Smiling at } \\
\text { personal } \\
\text { difficulties (SPD) }\end{array}$ & $2.69(0.83)$ & $2.12(0.88)$ \\
\hline
\end{tabular}

* Item 13 is reverse coded 

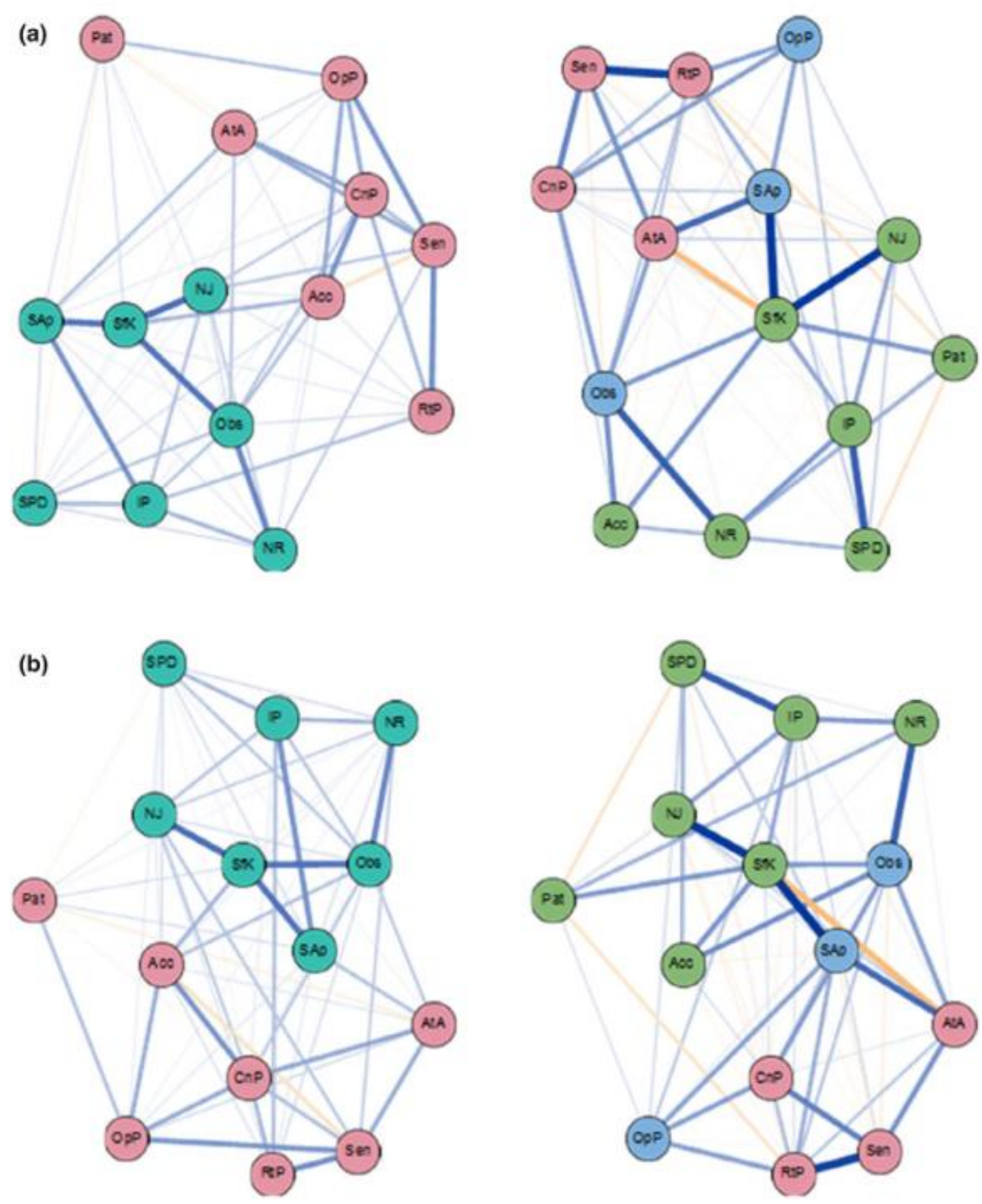

Figure 2. Glasso FMI mindfulness networks for practitioners (left) and nonpractitioners(right). Each node represents a questionnaire item (abbreviated; see Table 2). Each pathway represents the regularized covariance between two 
components. Thicker pathways signify stronger associations. Blue denotes a positive association and orange denotes a negative association. To assist comparisons, identical positioning (layout) of practices was imposed in the top networks. This involved taking the mean of the individual layouts represented in bottom figures. Minimum path weight for inclusion was set at 0 for both networks, and the maximum .38 (the maximum path value found across the networks). The gamma value used was .5. Graphs depict communities detected using the Exploratory Graphical Analysis package (EGA, Golino \& Epskamp, 2017). The Fruchterman-Reingold algorithm (Fruchterman \& Reingold, 1991) was used to layout all graphs. This algorithm tends to cause the most central nodes to migrate to the centre. 


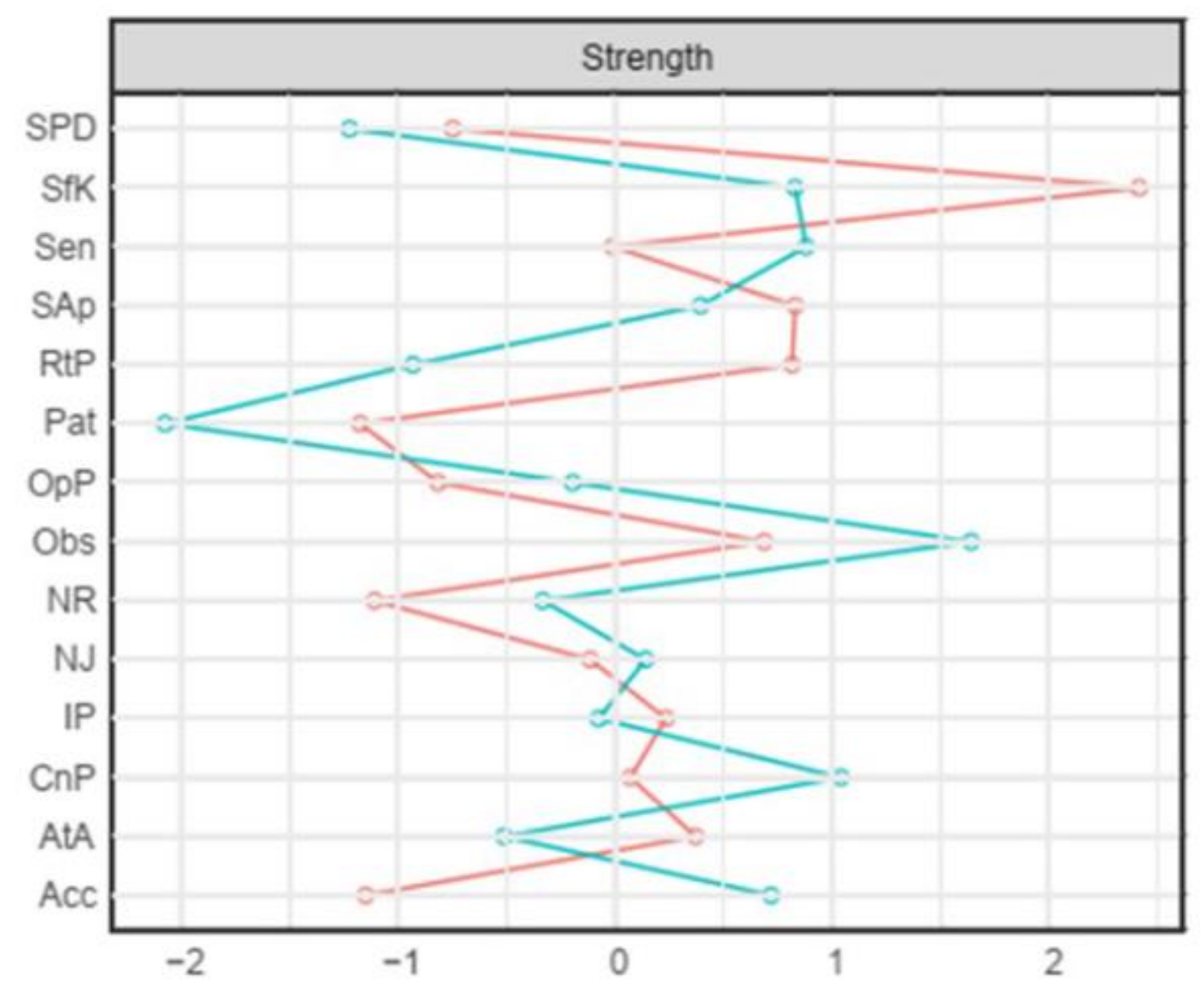

Figure 3. Standardized strength centrality values for practitioners' (blue) and nonpractitioners' (red) 14 item FMI mindfulness network. Z-scores are shown on x-axis rather than raw centrality indices to allow for comparison

Broad similarities were observed across the groups networks as evident in the strong correlation between the path weights of the practitioner's and non-practitioners' networks (co-efficient of similarity $r_{s}=.51$ ), and moderate to strong correlation of strength centrality $\left(r_{s}=.36\right)$. The EGA revealed two communities of items in the practitioner sample which closely resembled two-factor solutions recovered in previous 
factor analytic research (each community differing only in one item from the factor structures retrieved by Khols et al., 2009). Three communities of items were recovered in the non-practitioners' network.

In the practitioners' sample, a number of highly central practices (Decentred Observing, followed by Connected to the present, Sensing, SelfKindness and Acceptance) were identified. Bootstrapped statistical difference tests revealed no significant differences between the strength centrality values of these highly strength central practices suggesting that neither should be considered more prominent than another (Figure S6). By way of contrast, the non-practitioners' network was dominated by the highly strength central practice of Self-Kindness, which statistically differed from all other practices in that network (Figure S6).

The most substantive group differences in centrality were observed in the practices of Self-Kindness, Acceptance and Returning to the Present. Acceptance was substantively more central to the practitioners' network whilst Self-

Kindness and Returning to the Present were substantively more central to the nonpractitioners' network. To a lesser extent, differences were also observed in Decentered Observation, Sensing, Connected to the Present, Patience and Attending to Actions. A prominent negative edge between Self-Kindness and Attending to Actions was also revealed in the non-practitioners' network. Evidence of range restriction was found in the non-practitioners' sample (variation was moderately correlated with practice strength in the non-practitioners' sample rs $=.45$, but not in the practitioners $r s=-.08)$. A visual analysis of floor and ceiling effects suggested that this was unlikely to have biased network structure (Figure S5), but it may however, limit the 
generalizability of results. Mean levels of items did not appear to drive strength centrality in either sample (practitioners' rs $=-.06$ non-practitioners' $r s=-.24$ ).

\section{Discussion}

As a general point, the estimated networks revealed the plausibility of a network conceptualisation of mindfulness: plausible bidirectional edges (predictive associations) were revealed among all the items. Contrary to the main hypothesis, the majority of practitioners' and non-practitioners' resampled networks did not statistically differ in overall network density. There was support for a significant difference in network structure when networks were estimated with maximum sensitivity $(62 \%$ of 500 networks differed at $\mathrm{Y}=0$ ), but this decreased as sparser networks were estimated (which tends to make networks more similar).

While it was not clear why the main hypothesis was not supported, a lack of power cannot be ruled out. That said, null results have been reported in psychopathology network studies investigating density, suggesting that the concept

may require further refinement (e.g. Schweren et al., 2018; van Loo et al., 2018). It is clearly possible then that the density hypothesis may be false.

"Exploratory analyses of each network revealed interesting differences in the centrality of certain items within each network. Of particular interest was the high centrality of Acceptance in the practitioners' network, raising the hypothesis that this practice may be particularly sensitive to change with mindfulness or a related contemplative practice. Although future research with temporal data is required to investigate this, some indirect support for this hypothesis may be found in an interpretation of the unique negative edge revealed between Self- 
Kindness and Attending to Actions in the non-practitioners' network. Plausibly, this negative path may index a form of critical processing (i.e., increased attending to actions leading to less self-kindness) unique to the non-practitioner's group. In turn, the absence of this path in practitioners could be considered consistent with a large body of evidence associating the practise of mindfulness with less ruminating and self-critical thinking (e.g. see van der Velden et al., 2015 for review). On this view, it becomes unsurprising that that Acceptance was more central to the practitioners' network, for the term is almost the antonym for self-criticism.

Further support for this interpretation comes from a qualitative study of the FMI by Belzer et al (2013). They found that the Attending to Actions item was largely interpreted in the context of a moral evaluation for non-practitioners, consistent with the above interpretation. On the other hand, practitioners were found to interpret the item (more homogenously) in the context of "continuous action monitoring" (p. 40) or the "mere registration of impulses, emotions, behaviours of the self in the present moment" (p. 40). Taken together, these findings suggest that focusing interventions on increasing engagement in Acceptance may be particularly useful for increasing engagement in mindfulness practices in general. Targeting self-critical in thinking may be one way to bring this about.

Further parallels can be found between the results of this study and those obtained by Belzer et al., (2013). The wider set of practices in which centrality differences exist (items $3,5,7,8,9,10,13$ ) closely approximate those in which Belzer et al (2013) observed comprehension differences (items 1, 2, 3, 5, 7, 8, 10, 12). These items have also been shown by Sauer et al., 2015 to best discriminate 
between groups in a machine learning study on the FMI (see also the best performing algorithm in Sauer et al., 2018). If we assume that discrepancies do indicate comprehension differences, they are seemingly stable across different datasets. Although speculative, group level comprehension differences might also account for the differences in community structures observed in this study; namely, the more parsimonious and visually more discrete community structure in the practitioners' network might feasibly have come by way of greater homogeneity in item comprehension.

Two other practices demonstrated substantive differences in centrality; namely Returning to Present and Self-kindness. It is unclear why the former practice was peripheral in practitioners relative to non-practitioners, and comparison may be less helpful given that it is singled out in Belzer et al's (2013) study as exemplary of comprehension differences. With respect to Self-kindness; it is important to recognise that the practice was highly central to both groups' networks, and shared a remarkably similar topology. In fact the only substantive difference related to the aforementioned negative path it shared with Attending to Actions, present only in the non-practitioners network. This was taken as an absolute value in centrality estimation which is somewhat an arbitrary decision, and hence the centrality difference itself could be considered somewhat arbitrary. Irrespective of a formal practice, Selfkindness appears central to a mindfulness system.

In summary, modelling mindfulness as a network sees mindfulness as being constituted by observable practices and their synergistic relations. This has implications for how the development of mindfulness is conceptualised: Development is not a 
linear, does-dependant process where the researcher queries how much exemplified in mean scores. Rather, development unfolds in the wax and wane of connectivity: in how the practices work together. No mindfulness entity exists beyond observable practices, which means that the ends of mindfulness are simply its means at a later time point. Consistent with this, the very qualities which arise from mindfulness constitute precisely those required to cultivate the practice in the first place. Likewise, mindfulness instruction directs one solely to the means of any given activity granted it's the prefix 'mindful'. For example, one does not focus on the destination mindful walking. This interpretation is also consistent with the canonical Buddhist doctrine of impermanence from which mindfulness derives. Plausibly, it represents an advance in how we think about and represent mindfulness in research.

\section{Limitations.}

The most important limitation of this study relates to the inferences which can be derived from cross-sectional research; namely, that group level generalisations may not correspond to the causal mechanisms that characterise the development of mindfulness within persons (see Bos et al., 2017 for a discussion in the field of psychopathology). The cross-sectional networks estimated thus provide only a starting point in investigating how mindfulness practices relate to each other on average, and future ideographic research is needed to investigate the substantial heterogeneity which likely exists at the individual level.

Another important limitation relates to assumptions underpinning the density and centrality hypotheses; namely, that all the nodes required to capture a mindfulness system are included. The addition and omission of nodes may fundamentally 
change the nature of a network and hence the centrality of given nodes (and in turn network density). Comparable results across different measures (of different scope) are thus required to confirm the results obtained here. Finally, future research would benefit larger samples of equal size to allow for a simpler comparison of networks than the procedure used here.

\section{Disclosure statement}

None of the authors has a financial interest or benefit they have arising from the direct applications of their research.

\section{References}

Belzer, F., Schmidt, S., Lucius-Hoene, G., Schneider, J. F., Orellana-Rios, C. L., \& Sauer, S. (2013). Challenging the construct validity of mindfulness assessmenta cognitive interview study of the Freiburg Mindfulness Inventory. Mindfulness, 4(1), 33-44. https://doi.org/10.1007/s12671-012-0165-7

Black, D. S., \& Slavich, G. M. (2016). Mindfulness meditation and the immune system: a systematic review of randomized controlled trials. Annals of the New York Academy of Sciences, 1373(1), 13-24. https://doi.org/10.1111/nyas.12998

Bollen, \& Lennox (1991). Conventional wisdom on measurement: A structural equation perspective. Psychological Bulletin, 110(2), 305-14. https://doi.org/10.1037/0033-2909.110.2.305.

Borsboom, D. (2006). The attack of the psychometricians. Psychometrika, 71(3), 425. https://doi.org/10.1007/s11336-006-1447-6. 
Borsboom, D. (2017). A network theory of mental disorders. World Psychiatry, 16(1), 513. https://doi.org/10.1002/wps.20375.

Borsboom, D., Mellenbergh, G. J., \& van Heerden, J. (2003). The theoretical status of latent variables. Psychological Review, 110(2), 203-219. http://dx.doi.org/10.1037/0033-295X.110.2.203

Bos, F. M., Snippe, E., de Vos, S., Hartmann, J. A., Simons, C. J. P., van der Krieke, L., ... Wichers, M. (2017). Can we jump from cross-sectional to dynamic interpretations of networks? Implications for the network perspective in psychiatry. Psychotherapy and Psychosomatics, 86(3), 175-177. https://doi.org/10.1159/000453

Bringmann, L. F., Elmer, T., Epskamp, S., Krause, R. W., Schoch, D., Wichers, M., Wigman, J. T. W., \& Snippe, E. (2019). What do centrality measures measure in psychological networks? Journal of Abnormal Psychology, 128(8), 892-903. https://doi.org/10.1037/abn0000446

Chiesa, A., (2013). The difficulty of defining mindfulness: Current thought and critical issues. Mindfulness, 4, https://doi.org/10.1007/s12671-012-0123-4

Edwards, J. R., \& Bagozzi, R. P. (2000). On the nature and direction of relationships between constructs and measures. Psychological Methods, 5(2), 155-174. https://doi.org/10.1037/1082-989X.5.2.155

Epskamp, S, Borsboom, D., \& Fried, E. I. (2018). Estimating psychological networks and their accuracy: A tutorial paper. Behavior Research Methods, 50(1), 195212. https://doi.org/10.3758/s13428-017-0862-1 
Epskamp, S, Cramer, A. O. J., Waldorp, L. J., Schmittmann, V. D., \& Borsboom, D. (2012). qgraph: Network visualizations of relationships in psychometric data. Journal of Statistical Software, 48(1), 1-18. https://doi.org/10.18637/jss.v048.i04

Friedman, J., Hastie, T., \& Tibshirani, R. (2008). Sparse inverse covariance estimation with the graphical lasso. Biostatistics, 9(3), 432-441. https://doi.org/10.1093/biostatistics/kxm045

Fruchterman, T. M. J., \& Reingold, E. M. (1991). Graph Drawing by Force-Directed Placement. Software: Practice and Experience, 21(11). https://doi.org/10.1002/spe.4380211102

Garland, E. L., Farb, N. A., Goldin, P. R., \& Fredrickson, B. L. (2015). The mindfulnessto-meaning theory: Extensions, applications, and challenges at the attentionappraisal-emotion interface. Psychological Inquiry, 26(4), 377-387. https://doi.org/10.1080/1047840X.2015.1092493

Golino, H. F., \& Epskamp, S. (2017). Exploratory graph analysis: A new approach for estimating the number of dimensions in psychological research. PLOS ONE, 12(6), e0174035. https://doi.org/10.1371/journal.pone.0174035

Hölzel, B. K., Carmody, J., Vangel, M., Congleton, C., Yerramsetti, S. M., Gard, T., \& Lazar, S. W. (2011). Mindfulness practice leads to increases in regional brain gray matter density. Psychiatry Research, 191(1), 36-43. https://doi.org/10.1016/j.pscychresns.2010.08.006

Jones, P. J., Mair, P., \& McNally, R. J. (2018). Visualizing psychological networks: A tutorial in R. Frontiers in Psychology, 9. https://doi.org/10.3389/fpsyg.2018.01742 
Kabat-Zinn, J. (1994). Wherever You Go, There You Are: Mindfulness Meditation in Everyday Life. Hyperion.

Khoury, B., Lecomte, T., Fortin, G., Masse, M., Therien, P., Bouchard, V., ... Hofmann, S. G. (2013). Mindfulness-based therapy: a comprehensive meta-analysis. Clinical Psychology Review, 33(6), 763-771. https://doi.org/10.1016/j.cpr.2013.05.005

Kohls, N., Sauer, S., \& Walach, H. (2009). Facets of mindfulness - Results of an online study investigating the Freiburg Mindfulness Inventory. Personality and Individual Differences, 46(2), 224-230. https://doi.org/10.1016/j.paid.2008.10.009

Pelham, W. E., Gonzalez, O., Metcalf, S. A., Whicker, C. L., Witkiewitz, K., Marsch, L. A., \& Mackinnon, D. P. (2019). Evaluating the Factor Structure of Each Facet of the Five Facet Mindfulness Questionnaire. Mindfulness, 10, 2629-2646. https://doi.org/10.1007/s12671-019-01235-2

R Core Team (2019). R: A language and environment for statistical computing. $R$ Foundation for Statistical Computing. Vienna, Austria. URL https://www.Rproject.org/.

Rhemtulla, M., Fried, E. I., Aggen, S. H., Tuerlinckx, F., Kendler, K. S., \& Borsboom, D. (2016). Network analysis of substance abuse and dependence symptoms. Drug and Alcohol Dependence, 161, 230-237. https://doi.org/10.1016/j.drugalcdep.2016.02.005

Roca, P., Diez, G. G., Castellanos, N., \& Vazquez, C. (2019). Does mindfulness change the mind? A novel psychonectome perspective based on network 
analysis. PloS One, 14(7), e0219793.

https://doi.org/10.1371/journal.pone.0219793

Sauer, S., Buettner, R., Heidenreich, T., Lemke, J., Berg, C., \& Kurz, C. (2018). Mindful machine learning: Using machine learning algorithms to predict the practice of mindfulness. European Journal of Psychological Assessment, 34(1), 6-13. https://doi.org/10.1027/1015-5759/a000312

Sauer, S., Lemke, J., Zinn, W., Buettner, R., \& Kohls, N. (2015). Mindful in a random forest: Assessing the validity of mindfulness items using random forests methods. Personality and Individual Differences, 81, 117-123. https://doi.org/10.1016/j.paid.2014.09.011

Sauer, S., Walach, H., Offenbächer, M., Lynch, S., \& Kohls, N. (2011). Measuring mindfulness: A Rasch analysis of the Freiburg Mindfulness Inventory. Religions, 2(4), 693-706; https://doi.org/10.3390/rel2040693

Schmittmann, V. D., Cramer, A. O. J., Waldorp, L. J., Epskamp, S., Kievit, R. A., \& Borsboom, D. (2013). Deconstructing the construct: A network perspective on psychological phenomena. New Ideas in Psychology, 31(1), 43-53. https://doi.org/10.1016/j.newideapsych.2011.02.007

Schweren, L., Borkulo, C. D. van, Fried, E., \& Goodyer, I. M. (2018). Assessment of symptom network density as a prognostic marker of treatment response in adolescent depression. JAMA Psychiatry, 75(1), 98-100. https://doi.org/10.1001/jamapsychiatry.2017.3561 
Shankland, R., Kotsou, I., Cuny, C., Strub L., \& Brown N. (2017) Reducing current limitations in order to enhance the quality of subjective well-being research: The example of mindfulness. In Brulé, G., \& Maggino F,. (eds). Metrics of Subjective Well-Being: Limits and Improvements. Springer.

Terluin, B., Boer, M. R. de, \& Vet, H. C. W. de. (2016). Differences in connection strength between mental symptoms might be explained by differences in variance: Reanalysis of network data did not confirm staging. PLOS ONE, 11(11), e0155205. https://doi.org/10.1371/journal.pone.0155205

Vago, D. R., \& Silbersweig, D. A. (2012). Self-awareness, self-regulation, and selftranscendence (S-ART): A framework for understanding the neurobiological mechanisms of mindfulness. Frontiers in Human Neuroscience, 6, 296. https://doi.org/10.3389/fnhum.2012.00296

van Borkulo, C., Boschloo, L., Borsboom, D., Penninx, B. W. J. H., Waldorp, L. J., \& Schoevers, R. A. (2015). Association of symptom network structure with the course of depression. JAMA Psychiatry, 72(12), 1219-1226.

https://doi.org/10.1001/jamapsychiatry.2015.2079

van Borkulo, C., Boschloo, L., Kossakowski, J., Tio, P., Schoevers, R., Borsboom, D., \& Waldorp, L. (2017). Comparing network structures on three aspects: A permutation test. Psychological Methods. Advance online publication. https://doi.org/10.1037/met0000476

Van Dam, N. T., van Vugt, M. K., Vago, D. R., Schmalzl, L., Saron, C. D., Olendzki, A., ... Meyer, D. E. (2018). Mind the hype: A critical evaluation and prescriptive 
agenda for research on mindfulness and meditation. Perspectives on

Psychological Science, 13(1), 36-61. https://doi.org/10.1177/1745691617709589

van der Velden, A. M., Kuyken, W., Wattar, U., Crane, C., Pallesen, K. J., Dahlgaard, J., ... Piet, J. (2015). A systematic review of mechanisms of change in mindfulnessbased cognitive therapy in the treatment of recurrent major depressive disorder. Clinical Psychology Review, 37, 26-39. https://doi.org/10.1016/j.cpr.2015.02.001

van Loo, H. M., Van Borkulo, C. D., Peterson, R. E., Fried, E. I., Aggen, S.

H., Borsboom, D., \& Kendler, K. S. (2018). Robust symptom networks in recurrent major depression across different levels of genetic and environmental risk. Journal of Affective Disorders, 227, 313-322.

https://doi.org/10.1016/j.jad.2017.10.038

Walach, H., Buchheld, N., Buttenmüller, V., Kleinknecht, N., \& Schmidt, S. (2006). Measuring mindfulness—-the Freiburg Mindfulness Inventory (FMI). Personality and Individual Differences, 40(8), 1543-1555.

https://doi.org/10.1016/j.paid.2005.11.025

Waszczuk, M. A., Zavos, H. M. S., Antonova, E., Haworth, C. M., Plomin, R., \& Eley, T. C. (2015). A multivariate twin study of trait mindfulness, depressive symptoms, and anxiety sensitivity. Depression and Anxiety, 32(4), 254-261. 